\title{
Reliability and Cost of Diabetic Diets
}

\author{
SIR RONALD TUNBRIDGE, ${ }^{*}$ M.D. M.SC., F.R.C.P. ; J. H. WETHERILL, † M.B., CH.B., M.R.C.P.
}

\begin{abstract}
Cummary: In 1968 the actual food intake of 63 diabetic $\checkmark$ patients was recorded for a period of one week. The food consumption of 19 was found to be within $10 \%$ of that which had been prescribed for them at the diabetic clinic, but the food actually eaten by many of the other patients differed appreciably from the prescribed diet. Dietary control was more reliable in the younger patients and in those who required insulin. In many patients the food intake varied widely from day to day.

There was no obvious relation between the reliability of dietary control during this survey and the standard of diabetic control as recorded in the diabetic clinic. The findings of this survey were compared, where possible, with the results of a previous and similar survey conducted in 1948. In both surveys it was confirmed that the cost of the diet per week for diabetics was above that for the general population.
\end{abstract}

\section{Introduction}

Most diabetic patients are advised to adhere to some form of dietary control, and it is usual to stress that this is an important feature of the management of the disorder. In view of the emphasis which is placed on diet in the instructions given to diabetics, it is surprising that there has been little formal investigation of the accuracy with which patients follow dietary directions. In 1948 a survey was conducted in the diabetic clinic at the General Infirmary at Leeds (Tunbridge, 1949, 1953), and this showed that in a significant number of patients the amount of food actually consumed deviated widely from the prescribed diet.

A similar survey was repeated in 1968 , and from the information obtained it was possible to assess again how closely patients adhered to their diets.

In both surveys the cost of the diets based on local food prices was calculated.

\section{The Survey}

A complete record of the food intake of a selection of patients attending the diabetic clinic at the General Infirmary at Leeds was obtained during the week 27 April to 3 May 1968. One hundred and seven patients, all of whom lived within the Leeds postal area, were taken at random from a list of clinic attenders. These patients were, in the first instance, contacted by letter, and the basic plan and purpose of the survey was explained to them. Fuller information was sent to those who expressed willingness to co-operate in the survey, and they were in addition invited to attend an informal meeting at the hospital, where they had the opportunity to raise any questions.

Each patient was provided with a specially prepared booklet in which there was space for the recording of all items of food and drink consumed. Care was taken to ensure that this space was sufficient for the separate recording for each day. The booklets were distributed in the week preceding the survey,

* Professor of Medicine.

† Tutor in Medicine.

Department of Medicine, University of Leeds, the General Infirmary, Leeds LS1 3EX. being personally delivered to the patients at home by one of the 26 dietetic students. who acted as visitors during the period of the study.

The students were given full details of the survey and the major problems they might encounter. To ensure uniformity in the details recorded, standards of measurement were agreed on with the students and discussed with the patients. In addition to the initial visit the students met their patients on two further occasions-once during the week of the survey to give any necessary advice, and again shortly after completion to collect the booklets. The students when returning the booklets also provided their own comments on the patients' use of measures and on any special domestic circumstances which could have influenced their eating habits during the survey.

The students were purposely not informed of the diets which had been prescribed, and no attempt was made at any stage to encourage the patients to adhere more strictly than usual to any particular diet.

During the week of the survey the retail cost of food in Leeds was investigated. The price of various foods and sample diabetic diets was obtained in four different shopping areas. These areas were chosen with local knowledge to provide information on the actual cost of food, ranging from the cheapest to the most expensive.

At the completion of the survey the information received from each patient was examined and the daily food intake was measured in terms of the total calories. The variation in food intake from day to day was noted, and the average daily calorific intake was compared with the prescribed diet. The reliability of dietary control was classified as in the 1948 survey by allocating patients to one of the three following groups: satisfactory, when the actual intake was within $10 \%$ of the prescribed diet; tolerable, when the actual intake deviated $11-20 \%$ from the prescribed diet; and hopeless, when the actual intake deviated more than $20 \%$ from the prescribed diet.

In addition, where the information given by the patient was suitably detailed, the cost of the actual diet was calculated on the basis of the local retail food prices.

\section{Results}

One hundred and seven patients were invited to take part in the survey. Thirteen failed to reply, and 15 were for various reasons unable to co-operate. Three of the remaining 79 changed their minds before the survey started and a further 13 failed to complete their booklets; thus the results of this survey are based on the completed records obtained from 63 patients ( 35 females and 28 males) aged 15 to 81 (average 56) years.

The reliability of dietary control for the whole group is shown in Table I. The standard of control was determined by

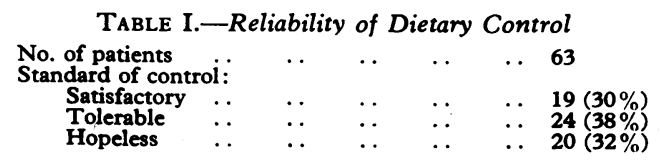


comparing the actual food intake of each patient with the diet which had been prescribed.

The relationship between the reliability of dietary control and other relevant factors are shown in Tables II-VI. The standard of control has been related to the sex and age of the patients (Table II) the nature of any supplementary diabetic therapy and the duration of diabetes mellitus (Table III), and the calorific value of the prescribed diet (Table IV).

Table II.-Dietary Control Related to Sex and Age

\begin{tabular}{|c|c|c|c|c|c|}
\hline & \multicolumn{2}{|c|}{ Sex } & \multicolumn{3}{|c|}{ Age } \\
\hline & Females & Males & 40 or less & $41-60$ & Over 60 \\
\hline No. of patients $\quad$. & 35 & 28 & 13 & 21 & 29 \\
\hline $\begin{array}{ll}\text { Satisfactory } & \\
\text { Tolerable } & \ldots \\
\text { Hopeless } & \ldots\end{array}$ & $\begin{array}{l}10 \\
13 \\
12\end{array}$ & $\begin{array}{r}9 \\
11 \\
8\end{array}$ & $\begin{array}{l}6 \\
4 \\
3\end{array}$ & $\begin{array}{r}5 \\
10 \\
6\end{array}$ & $\begin{array}{r}8 \\
10 \\
11\end{array}$ \\
\hline
\end{tabular}

TABLE III.-Dietary Cantrol Related to Diabetic Therapy

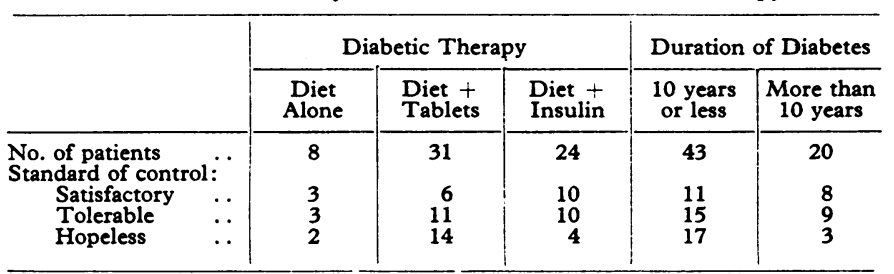

TABLE IV.-Dietary Control Related to Prescribed Diet

\begin{tabular}{|c|c|c|c|}
\hline & \multicolumn{3}{|c|}{ Calories } \\
\hline & 1,200 or less & $1,201-1,999$ & 2,000 or more \\
\hline $\begin{array}{l}\text { No. of patients ... } \\
\text { Standard of control: } \\
\text { Satisfactory } \\
\text { Tolerable . } \\
\text { Hopeless ... }\end{array}$ & $\begin{array}{r}20 \\
4 \\
6 \\
10\end{array}$ & $\begin{array}{r}29 \\
12 \\
9 \\
8\end{array}$ & $\begin{array}{r}14 \\
3 \\
9 \\
2\end{array}$ \\
\hline
\end{tabular}

The information obtained during the survey was also used in assessing the cost of diabetic diets. The average diet which had been prescribed for patients included in the survey was found to be equivalent to 1,550 calories. An ideal diabetic diet of this calorific value was prepared and its cost was then determined with reference to the retail price of food in Leeds during the week of the survey. The cost of the diets actually consumed was then calculated on a similar basis. In many cases it was found that the information supplied was not detailed enough for an accurate determination of the cost of the food, but it was possible to assess the cost of the diet of 12 patients with confidence. The results of these calculations are given in Table $\mathrm{V}$.

\begin{tabular}{|c|c|c|c|c|}
\hline Ideal diabetic diet & $\left\{\begin{array}{l}\text { Lowest possible cost } \\
\text { Highest possible cost } \\
\text { Probable actual cost }\end{array}\right.$ & $\begin{array}{l}\cdots \\
\cdots\end{array}$ & $\begin{array}{l}\cdots \\
\cdots \\
\cdots\end{array}$ & $\begin{array}{l}\ldots \text { 33s. 5d. per week } \\
\therefore \text { 49s. 6d. per week } \\
\therefore \text { 44s. 1d. per week }\end{array}$ \\
\hline Actual diabetic diets & $\left\{\begin{array}{l}\text { Lowest possible cost } \\
\text { Highest possible cost } \\
\text { Probable actual cost }\end{array}\right.$ & $\begin{array}{l}\cdots \\
\cdots\end{array}$ & $\begin{array}{l}\cdots \\
\cdots\end{array}$ & $\begin{array}{l}\text {. 28s. Od. per week } \\
\therefore \text { 69s. Od. per week } \\
\therefore \text { 49s. 3d. per week }\end{array}$ \\
\hline
\end{tabular}

Cost of food per head of general population 38s. 4d. per week

\section{Discussion}

Perhaps the most noticeable finding in this survey was that slightly less than one-third of the patients were keeping within $10 \%$ of their prescribed diet. This may seem to be a disappointing proportion, but, in fact, it was similar to that found in 1948. The comparative findings for the two surveys are shown in Table VI.
TABLE VI.-Comparison of Two Dietary Surveys

\begin{tabular}{|c|c|c|c|c|c|}
\hline & & & & 1948 & 1968 \\
\hline $\begin{array}{cc}\begin{array}{l}\text { No. of patients } \\
\text { Standard of control: } \\
\begin{array}{c}\text { Satisfactory } \\
\text { Tolerable }\end{array} \\
\text { Hopeless .. }\end{array} & \ldots \\
& \ldots\end{array}$ & $\begin{array}{l}\cdots \\
\cdots \\
\cdots\end{array}$ & $\begin{array}{l}\cdots \\
\cdots \\
\cdots\end{array}$ & $\begin{array}{l}\cdots \\
\cdots \\
\cdots\end{array}$ & $\begin{array}{c}94 \\
16(17 \%) \\
44(47 \%) \\
34(36 \%)\end{array}$ & $\begin{array}{c}63 \\
19(30 \%) \\
24(38 \%) \\
20(32 \%)\end{array}$ \\
\hline
\end{tabular}

It is of interest that though an identical number of patients (107) were invited to co-operate in each survey there was numerically a significantly poorer response in 1968 .

There is no evidence to suggest that the standard of dietary control in diabetics which is shown in these surveys is in any way atypical of what would be found on wider inquiry. The figures are comparable to those reported by Bloom (1967). In a survey of diets based on single but searching interviews he found that 17 out of 111 insulin-dependent diabetics adhered strictly and regularly to their prescribed diet, while 60 adhered in a general way, and the other 34 were unable to follow any regular diet.

In our survey there was a definite preponderance of elderly patients among those whose dietary control was poor, and a strong suggestion that control was especially likely to be poor in patients who also received oral hypoglycaemic agents. These findings may help in identifying which groups of patients are unlikely to be following dietary directions, but a more basic question is raised by these surveys. What is the relation between dietary and diabetic control?

Bloom (1967) found that the average blood sugar levels found in the diabetic clinic were unrelated to the standard of dietary control, and were similar in all groups. He also reported a significant relationship between dietary control and the severity of hypoglycaemic reactions-patients who did not adhere to their diet were much less likely to have severe reactions.

In our survey also we have compared dietary and diabetic control. Diabetic control was assessed on the findings for each patient at the four visits to the clinic which were nearest in time to the week of the survey. If at all these visits the blood glucose level was between 50 and $200 \mathrm{mg}$. $/ 100 \mathrm{ml}$., there was no ketonuria, and the weight remained steady, then the control was assessed as satisfactory. Any deviation from the above criteria was considered to be unsatisfactory. With this strict definition, there appears to be no obvious relation between dietary and diabetic control as shown in Table VII.

TABle VII.-Comparison of Dietary and Diabetic Control

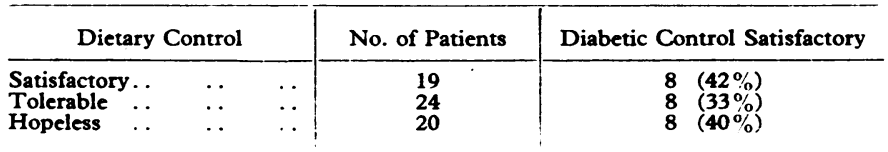

When comparing the two Leeds surveys it is important to note that they were separated by 20 years, during which time a number of important changes had occurred. There had been a general increase in the standard of living, abolition of all forms of food rationing (the diabetic had been allowed special rations), and the development of the National Health Service. There were also local changes in the manner in which dietary advice was given in the diabetic clinic. During the two years preceding the 1948 survey regular teaching sessions were held in the clinic, at which a physician and dietitian discussed all aspects of diet and to which all patients were invited. In recent years this method has been replaced by more intensive personal instruction from the dietitians. Patients have the opportunity to talk with a dietitian whenever they attend the clinic, and even if no particular problems arise every effort is made for them to be seen by a dietitian for a dietary review at sixmonthly intervals. 
In 1948 it was noted that whatever the standard of dietary control there was little variation in food intake from day to day. In some patients there was a tendency for a reduction of food intake towards the end of the week, and this was assumed to indicate an element of financial difficulty before pay or pension day, especially as it was more obvious in patients with limited means. In complete contrast, in 1968 there were considerable fluctuations in intake from day to day, with no particular pattern discernible during the week. Some variability was noted even in those patients who, on average, were keeping close to the prescribed diet. The extreme example of such variation was in a diet which ranged from 1,265 to 2,850 calories per day within the week, the patient, perhaps surprisingly, was a woman aged 63 . Though these fluctuations may have an adverse effect on blood glucose levels they are in keeping with the variations observed in normal people, and are presumably related to the changing energy requirements from day to day. Booyens and McCance (1957) showed that in six normal subjects there was a wide range of daily food intake, the calorific intake varying from an average of 2,114 to 3,007 calories during a one-week or two-week period.

There are obviously many social and economic factors which influence a diabetic patient's ability and desire to follow dietary advice. One factor is the cost of the diabetic diet, and this was assessed in both Leeds surveys. In 1948 it was found that the average weekly cost of food for diabetics was $23 \mathrm{~s}$., while the average cost of food for the non-diabetic members of the same families was just over 10s. In 1968 the cost of an ideal diabetic diet, of the same calorific value as the average prescribed for the patients in the survey, was found to be $44 \mathrm{~s}$. 1d. This figure was calculated after a careful survey of the range of local retail prices. The probable average cost is not the arithmetical mean of the lowest and highest possible cost. It is unlikely that many patients would buy food at the highest prices and even more unlikely that they could buy all their food at the cheapest prices, for these were usually limited to one area within the city. We have therefore assumed, after reviewing the patients' records and the range of prices for each item of food, that the probable actual cost of each item was the minimum cost plus two-thirds of the difference between minimum and maximum costs.

In assessing the cost of the diets actually consumed it was found that many patients failed to identify their food in sufficient detail for a confident calculation to be made. In those cases where the information supplied was adequate the probable actual cost, on average, was $49 \mathrm{~s}$. $3 \mathrm{~d}$. Though the results of these calculations must be accepted with caution, they all indicate that the cost of food for diabetics is higher than for non-diabetics (38s. 4d.) (National Food Survey, 1968), and support the clinical finding that patients with low incomes continue to have difficulty in purchasing a correct diet.

We would like to acknowledge the help we received during this survey from all the patients who co-operated; Miss Boyle, senior lecturer in the department of nutrition and dietetics; the dietetic students at the Leeds College of Technology; Miss Conry, chief dietitian to the United Leeds Hospitals; and Miss Spence, secretary in the department of medicine.

\section{REFERENCES}

Bloom, A. (1967). Proceedings of the Royal Society of Medicine, 60, 149. Booyens, J., and McCance, R. A. (1957). Lancet, 1, 225.

National Food Survey (1966). Board of Trade fournal, 195, 922.

Tunbridge, R. E. (1949). British Medical fournal, 2, 70.

Tunbridge, R. E. (1953). Lancet, 2, 893.

\section{Subclinical Neuropathy in Lead Workers}

\section{J. CATTON, ${ }^{*}$ M.B., D.P.H. ; M. J. G. HARRISON, $\ddagger$ D.M., M.R.C.P. ; PAMELA M. FULLERTON, $\dagger$ D.M., M.R.C.P.}

$$
\text { G. KAZANTZIS, } \ \text { PH.D., M.R.C.P. }
$$

$\mathrm{S}$ ummary: Evidence is presented for a minimal defect of peripheral nerve function in a group of lead accumulator. workers without clinical evidence of a neurological lesion. Of the 19 men examined, 13 had blood levels above $80 \mu \mathrm{g} . / 100 \mathrm{ml}$. and seven had haemoglobin levels below $12 \mathrm{~g} . / 100 \mathrm{ml}$, showing that considerable exposure to lead was occurring.

\section{Introduction}

Exposure to lead is still an occupational hazard, and leadpoisoning remains the commonest notifiable industrial disease in Great Britain (Department of Health and Productivity, 1968). Lead palsy, at one time common, is now rare in clinical practice. It is possible, however, that exposed workers might develop minor degrees of peripheral nerve damage, insufficient to cause symptoms or signs. Lloyd Davies (1965) discussed the problem of subclinical damage in relation to other aspects of lead-poisoning.

* H.M. Divisional Medical Inspector of Factories, London.

† Consultant Neurologist, Middlesex Hospital, London W.1; Part-time Member, M.R.C. Toxicology Unit, Carshalton, Surrey.

¥ Registrar, Department of Neurology, Middlesex Hospital, London W.1.

o Senior Lecturer in Social and Preventive Medicine, Middlesex Hospital, London $W .1$.
Experimentally a neuropathy can be produced in guineapigs by chronic lead intoxication (Gombault, 1880). The main pathological change in the peripheral nerve fibres consists of segmental demyelination and may be associated with pronounced slowing of nerve conduction velocity (Fullerton, 1966). There have been a few previous studies of nerve conduction velocity in lead workers, both with and without clinical evidence of toxicity. Delwaide and Chantraine (1965) investigated 12 patients and found that, even in the presence of considerable muscle wasting, motor conduction velocity was below the lower limit of normal in only one subject. Simpson, Seaton, and Adams (1964) also found normal motor conduction in a patient with a neurological disorder attributed to lead intoxication. On the other hand, in two other studies slight changes in conduction velocity were found in workers without any abnormal neurological symptoms or signs (Bergamini and Sibour, 1960; Sessa, Ferrari, and d'Amato, 1965). Thus slight reduction in conduction velocity has been found in lead workers on a few occasions, but changes comparable to those seen in guinea-pigs with lead neuropathy have not been described in man.

In view of continuing doubt about the nature of the peripheral nerve lesion in man and the level of exposure at which subclinical damage might occur, a further study of exposed workers has been carried out, a preliminary report of which has already appeared (Fullerton, 1969). 